九州大学学術情報リポジトリ

Kyushu University Institutional Repository

\title{
Synthesis and photocatalytic activity of mesoporous SiO_2-TiO_2
}

Inada, Miki

Department of Applied Chemistry, Faculty of Engineering, Kyushu University

Enomoto, Naoya

Department of Applied Chemistry, Faculty of Engineering, Kyushu University

Hojo, Junichi

Department of Applied Chemistry, Faculty of Engineering, Kyushu University

http://hdl. handle. net/2324/26617

出版情報: Research on Chemical Intermediates. 36 (1)，pp.115-120，2010-01. Springer Nether lands

バージョン:

権利関係: (C) Springer Science+Business Media B. V. 2010 


\section{Synthesis and Photocatalytic Activity of Mesoporous $\mathrm{SiO}_{2}-\mathrm{TiO}_{2}$}

\section{Miki INADA, Naoya ENOMOTO and Junichi HOJO*}

Department of Applied Chemistry, Faculty of Engineering, Kyushu University, 744 Motooka, Nishi-ku, Fukuoka, 819-0395 Japan

*Author to whom correspondence should be addressed.

Junichi HOJO,

Tel and Fax: $\quad+81-92-802-2859$

e-mail: $\quad$ jhojo@cstf.kyushu-u.ac.jp

Address: $\quad$ Department of Applied Chemistry, Faculty of Engineering, Kyushu University, 744 Motooka, Nishi-ku, Fukuoka, 819-0395 Japan 


\begin{abstract}
Mesoporous $\mathrm{SiO}_{2}-\mathrm{TiO}_{2}$ was synthesized by sol-gel method using $\mathrm{Si}\left(\mathrm{OC}_{2} \mathrm{H}_{5}\right)_{4}$, $\mathrm{Ti}\left(\mathrm{OC}_{2} \mathrm{H}_{5}\right)_{4}$ and stearyltrimethylammonium chloride. By using acetylacetone as the capping agent of $\mathrm{Ti}\left(\mathrm{OC}_{2} \mathrm{H}_{5}\right)_{4}$, homogeneous $\mathrm{SiO}_{2}-\mathrm{TiO}_{2}$ composite was obtained. Spherical mesoporous $\mathrm{SiO}_{2}-\mathrm{TiO}_{2}$ was also synthesized by sol-gel method using $\mathrm{W} / \mathrm{O}$ emulsion under microwave irradiation. The specific surface area of these mesoporous $\mathrm{SiO}_{2}-\mathrm{TiO}_{2}$ materials decreased when $\mathrm{Ti} / \mathrm{Si}$ molar ratio was higher than 0.1 , which indicated that $\mathrm{Ti}$ was homogeneously distributed in mesoporous $\mathrm{SiO}_{2}$ matrix at $\mathrm{Ti} / \mathrm{Si} \leqq 0.1$. Photocatalytic activity of mesoporous $\mathrm{SiO}_{2}-\mathrm{TiO}_{2}$ materials was investigated by degradation of methylene-blue in water under UV light irradiation. Mesoporous $\mathrm{SiO}_{2}-\mathrm{TiO}_{2}$ was effective for the adsorption-decomposition of methylene-blue.
\end{abstract}

\title{
KEYWORDS
}

Mesoporous silica, titania, spherical particle, sol-gel, photocatalyst 


\section{Introduction}

Mesoporous silica is useful as adsorbents in gas or liquid phase and catalyst support. Regularly-oriented mesoporous structure is formed by a sol-gel process using the self-assembly of organic surfactant as template [1]. The gas adsorbability of mesoporous silica is remarkably enhanced by addition of other metal oxides, especially $\mathrm{TiO}_{2}$, forming acidic points [2-4]. Although the sol-gel method using metal alkoxides is easy to synthesis mesoporous silica composite, there is a problem in the difference of hydrolysis rate between various starting alkoxides. The authors have studied the process factors on formation of $\mathrm{SiO}_{2}-\mathrm{TiO}_{2}$ mesoporous materials from $\mathrm{Si}$ and $\mathrm{Ti}$ alkoxides, and found that the way for homogenization is the partial hydrolysis of Si alkoxide before the addition of Ti alkoxide [4-6].

We have also synthesized spherical mesoporous silica materials by microwaveemulsion method [7]. In the microwave-emulsion method, n-hexane was used as oil phase, because n-hexane does not absorb microwave, and aqueous solution including silica source and template of mesopores as water phase. When microwave is irradiated to the W/O emulsion, water phase is heated selectively and sol-gel reaction proceeds in water phase, resulting in formation of spherical mesoporous silica.

In this study, homogeneous $\mathrm{SiO}_{2}-\mathrm{TiO}_{2}$ mesoporous materials were synthesized by using acetylacetone as capping agent of $\mathrm{Ti}$ alkoxide. In addition, spherical mesoporous $\mathrm{SiO}_{2}-\mathrm{TiO}_{2}$ was synthesized by microwave-emulsion method and the photocatalytic activity was compared with bulk sample.

\section{Experimental Procedure}

\subsection{Synthesis of mesoporous $\mathrm{SiO}_{2}$ and $\mathrm{SiO}_{2}-\mathrm{TiO}_{2}$}

Mesoporous $\mathrm{SiO}_{2}$ and $\mathrm{SiO}_{2}-\mathrm{TiO}_{2}$ were synthesized by sol-gel method using $\mathrm{Si}\left(\mathrm{OC}_{2} \mathrm{H}_{5}\right)_{4}$ (TEOS; Wako Pure Chemical Industries, Ltd.) and Ti( $\left(\mathrm{OC}_{2} \mathrm{H}_{5}\right)_{4}$ (TEOT; Merck KGaA, Co.). 
First, TEOT was capped with acetylacetone to control the reactivity, because the hydrolysis rate of TEOT was higher than that of TEOS. TEOT was mixed with acetylacetone in dry $\mathrm{N}_{2}$ at the ratio of TEOT to acetylacetone $=1: 2$ in mol. After stirring for 30min, TEOS, stearyltrimethylammonium chloride $\left(\mathrm{C}_{18} \mathrm{TAC}\right.$; Nacalai Tesque, Inc.) as template and diluted $\mathrm{HCl}$ water $(\mathrm{pH}=2)$ were added to the capped TEOT solution, and then heated at $50{ }^{\circ} \mathrm{C}$. The composition was set at TEOS: $\mathrm{C}_{18} \mathrm{TAC}: \mathrm{H}_{2} \mathrm{O}=1: 0.2: 20$ in mol. The Ti/Si molar ratio in the composite was changed from 0.1 to 0.5 . After sol-gel reaction was proceeded completely, the gel was calcined in air at $500{ }^{\circ} \mathrm{C}$ for $4 \mathrm{~h}$ at $2{ }^{\circ} \mathrm{C} / \mathrm{min}$ in order to remove the organic template.

\subsection{Synthesis of spherical mesoporous $\mathrm{SiO}_{2}$ and $\mathrm{SiO}_{2}-\mathrm{TiO}_{2}$}

Microwave-emulsion method was applied to synthesize the spherical mesoporous $\mathrm{SiO}_{2}$ and $\mathrm{SiO}_{2}-\mathrm{TiO}_{2}$. The procedure has already been reported as ref.[7]. Figure 1 shows the flow chart for synthesis of spherical mesoporous $\mathrm{SiO}_{2}-\mathrm{TiO}_{2}$. In order to prepare oil phase of W/O emulsion, n-hexane was mixed with $10 \mathrm{wt} \%$ of polyglycerol polyricinalate (PP) as emulsifier. On the other hand, TEOS was added to capped-TEOT solution prepared as above and mixed with diluted $\mathrm{HCl}$ water $(\mathrm{pH}=2)$ including $\mathrm{C}_{18}$ TAC. After stirring for $1.5 \mathrm{~h}$ at $50{ }^{\circ} \mathrm{C}$, partially hydrolyzed TEOS-TEOT solution was obtained. The composition was set at TEOS: $\mathrm{C}_{18} \mathrm{TAC}: \mathrm{H}_{2} \mathrm{O}=1: 0.28: 56$ in mol. The Ti/Si molar ratio in the composite was changed from 0.1 to 1.0. The water phase, prepared by addition of $5 \mathrm{ml}$ of $\mathrm{H}_{2} \mathrm{O}$ to the partially hydrolyzed TEOS-TEOT solution, was mixed with oil phase under stirring, resulting in W/O emulsion. The microwave heating process was performed by using the MARS5X (CEM Co.) microwave digestion system. The reaction was carried out in a sealed Teflon vessel under stirring with a magnetic stirrer and the reacting temperature was set at $60{ }^{\circ} \mathrm{C}$ for $30 \mathrm{~min}$. After heating, the precipitate was separated by centrifugation. The produced powder was washed 
with ethanol and distilled water, and then dried at $100{ }^{\circ} \mathrm{C}$. In order to remove the organic residue, the dried products were calcined at $500{ }^{\circ} \mathrm{C}$ for $4 \mathrm{~h}$ at $2{ }^{\circ} \mathrm{C} / \mathrm{min}$ in air.

\subsection{Characterization}

The morphology of products was observed by scanning electron microscopy (SEM; S5200, Hitachi Co.). The specific surface area and average pore size of calcined products were determined from $\mathrm{N}_{2}$ adsorption isotherm by the BET method (Belsorp 18SP, BelJAPAN, Inc.). Acidity was measured by amine titration in benzene using $p$-dimethylaminoazobenzene as an indicator. Photocatalytic activity was determined by degradation of methylene-blue in water under UV light irradiation. Black light (FL6-BLB, Toshiba Lighting and Technology, Co.) was used as light source and the wavelength was $352 \mathrm{~nm}$. The absorption spectrum of methylene-blue was measured at $\lambda=664 \mathrm{~nm}$ with a UV-Visible spectrometer (U-3300, Hitachi Co.).

\section{Results and discussion}

Homogeneous $\mathrm{SiO}_{2}-\mathrm{TiO}_{2}$ mesoporous materials were synthesized by using acetylacetone as capping agent of $\mathrm{Ti}$ alkoxide. The typical SEM image of spherical mesoporous $\mathrm{SiO}_{2}-\mathrm{TiO}_{2}$ synthesized by microwave-emulsion method is shown in Fig. 2. Most particles were spherical and the particle size was 0.1-20 $\mu \mathrm{m}$. Some broken particles were observed, indicating the formation of solid particles. As the Ti/Si molar ratio became higher, the morphology of particles changed to irregular. However, the XRD peaks of anatase and/or rutile were not detected even at $\mathrm{Ti} / \mathrm{Si}=0.5$. These results indicated that $\mathrm{TiO}_{2}$ was not formed separately from $\mathrm{SiO}_{2}$ network and homogeneous incorporation of $\mathrm{Ti}$ to $\mathrm{Si}-\mathrm{O}$ network was achieved by using acetylacetone to control the hydrolysis rate of TEOT. Figure 3 shows the change in the specific surface area of bulk and spherical mesoporous $\mathrm{SiO}_{2}-\mathrm{TiO}_{2}$ with $\mathrm{Ti} / \mathrm{Si}$ 
molar ratio. In both cases, the specific surface area was kept high up to $\mathrm{Ti} / \mathrm{Si}=0.1$, and then decreased with an increase in Ti/Si molar ratio. In addition, $\mathrm{N}_{2}$ adsorption isotherms of bulk and spherical samples at $\mathrm{Ti} / \mathrm{Si} \leqq 0.1$ were Type IV. These results indicated that the mesoporous $\mathrm{SiO}_{2}$ structure was maintained even in the presence of $\mathrm{Ti}$ less than $\mathrm{Ti} / \mathrm{Si}=0.1$. The BJH pore size of both samples at $\mathrm{Ti} / \mathrm{Si}=0.1$ was $3.4 \mathrm{~nm}$. Acidity of bulk sample reached the maximum value at $\mathrm{Ti} / \mathrm{Si}=0.1$, and then decreased (Fig.4). This means that $\mathrm{Ti}$ was homogeneously distributed in $\mathrm{Si}-\mathrm{O}$ network at $\mathrm{Ti} / \mathrm{Si} \leqq 0.1$ like $-\mathrm{Si}-\mathrm{O}-\mathrm{Ti}-\mathrm{O}-\mathrm{Si}$-. At $\mathrm{Ti} / \mathrm{Si}>0.1$, $\mathrm{TiO}_{2}$ cluster began to generate in $\mathrm{Si}-\mathrm{O}$ network like $-\mathrm{Si}-\mathrm{O}-\mathrm{Ti}-\mathrm{O}-\mathrm{Ti}-\mathrm{O}-\mathrm{Si}$-, which led to a decrease in acidity. Furthermore, $\mathrm{TiO}_{2}$ cluster may be isolated from $\mathrm{Si}-\mathrm{O}$ network at $\mathrm{Ti} / \mathrm{Si}>0.5$. The same result was obtained in the case of spherical mesoporous $\mathrm{SiO}_{2}-\mathrm{TiO}_{2}$.

Photocatalytic activity of bulk and spherical mesoporous $\mathrm{SiO}_{2}-\mathrm{TiO}_{2}$ was determined by degradation of methylene-blue (MB) in water. The $20 \mathrm{mg}$ of powder sample was suspended in $100 \mathrm{ml}$ of $50 \mu \mathrm{M} \mathrm{MB}$ aqueous solution. The change of MB concentration by adsorption was pursued for $14 \mathrm{~h}$ under dark condition, and then that by photocatalytic decomposition for $7 \mathrm{~h}$ under UV light irradiation. Figure 5 shows the change in MB concentration with time. The adsorption and decomposition of $\mathrm{MB}$ were not observed on both bulk and spherical mesoporous $\mathrm{SiO}_{2}$. In the case of $\mathrm{SiO}_{2}-\mathrm{TiO}_{2}$ materials, $\mathrm{MB}$ concentration significantly decreased within $14 \mathrm{~h}$ under dark condition, and then decreased with time under UV light irradiation. This means that $\mathrm{MB}$ adsorbed on acid point of $\mathrm{SiO}_{2}-\mathrm{TiO}_{2}$ samples and photodecomposition proceeded on acid point under UV light irradiation. The morphology of mesoporous $\mathrm{SiO}_{2}-\mathrm{TiO}_{2}$ did not so much influence on the photocatalytic activity.

\section{Conclusions}

In this study, homogeneous $\mathrm{SiO}_{2}-\mathrm{TiO}_{2}$ mesoporous materials without the separate deposition of $\mathrm{TiO}_{2}$ could be synthesized by using acetylacetone as capping agent of $\mathrm{Ti}$ 
alkoxide. Spherical mesoporous $\mathrm{SiO}_{2}-\mathrm{TiO}_{2}$ was also synthesized by microwave-emulsion method. The results of specific surface area and acidity indicated that Ti was homogeneously distributed in $\mathrm{Si}-\mathrm{O}$ network less than $\mathrm{Ti} / \mathrm{Si}=0.1$. The adsorption-decomposition of $\mathrm{MB}$ may proceed on the acid point. 


\section{References}

1. C. T. Kresge, M. E. Leonowicz, W. J. Roth, J. C. Vrtuli and J. S. Beck, Nature 359 (1992) 710.

2. S. Zheng, L. Gao, Q. Zhang and J. Guo, J. Mater. Chem. 10 (2000) 723.

3. S. Zheng, L. Gao, Q. Zhang, W. Zhang and J. Guo, J. Mater. Chem. 11 (2001) 578.

4. X. Y. Li, M. Uehara, N. Enomoto and J. Hojo, Trans. Mater. Soc. Jpn. 26 (2) (2001) 499.

5. X. Y. Li, M. Uehara, N. Enomoto and J. Hojo, J. Ceram. Soc. Jpn. 109 (10) (2001) 818.

6. N. Enomoto, K. Kawasaki, M. Yoshida, X. Y. Li, M. Uehara and J. Hojo, Solid State Ionics, $151(2002) 171$.

7. M. Inada, A. Nishinosono, K. Kamada, N. Eenomoto, J. Hojo, J. Mater. Sci. 43 (7) (2008) 2362. 


\section{Figure legends}

Fig. 1 Flow chart for synthesis of spherical mesoporous $\mathrm{SiO}_{2}-\mathrm{TiO}_{2}$.

Fig. 2 SEM images of spherical mesoporous $\mathrm{SiO}_{2}-\mathrm{TiO}_{2}$ at $\mathrm{Ti} / \mathrm{Si}=0.1$ synthesized by microwave-emulsion method.

Fig. 3 Change in specific surface area of bulk and spherical mesoporous $\mathrm{SiO}_{2}-\mathrm{TiO}_{2}$ with Ti/Si molar ratio.

Fig. 4 Change in acidity of bulk mesoporous $\mathrm{SiO}_{2}-\mathrm{TiO}_{2}$ with $\mathrm{Ti} / \mathrm{Si}$ molar ratio.

Fig. 5 Change in MB concentration with time. 


\section{Figure}

Fig.1

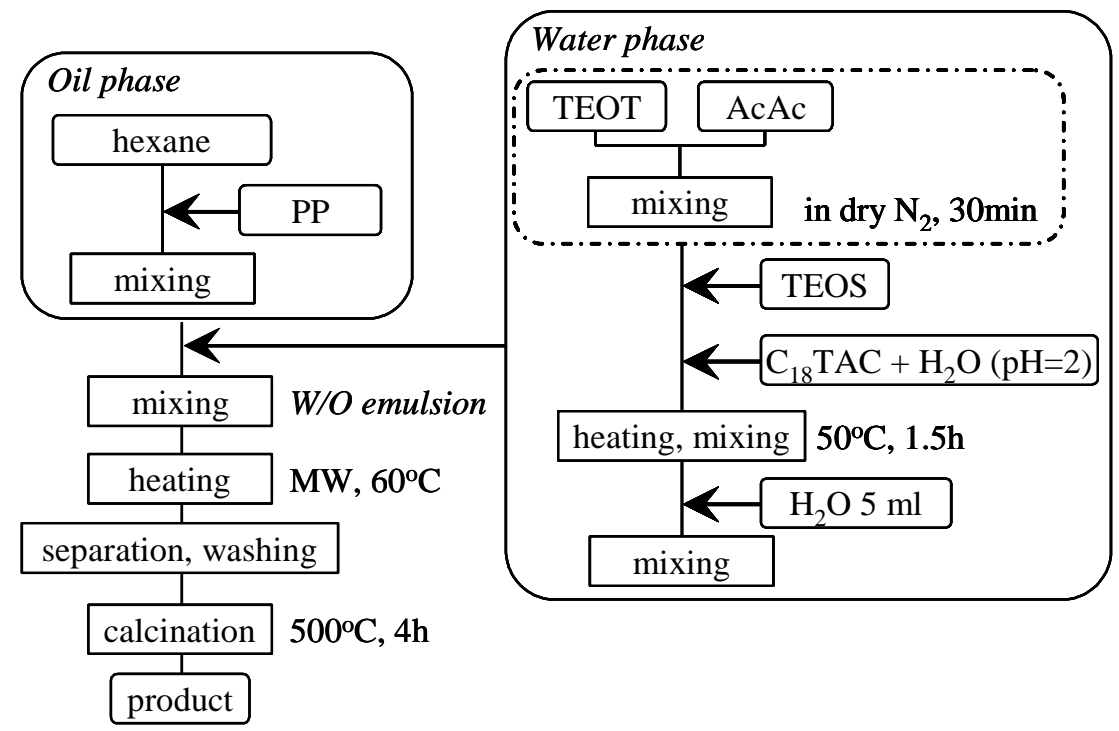


Fig. 2

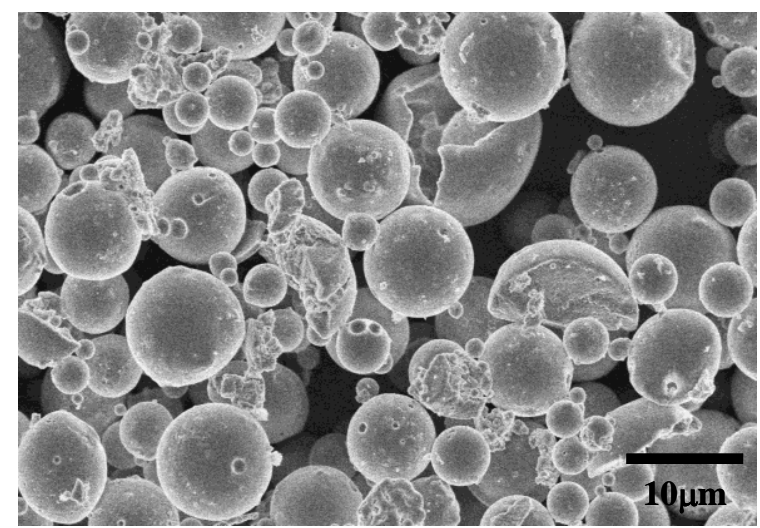


Fig.3

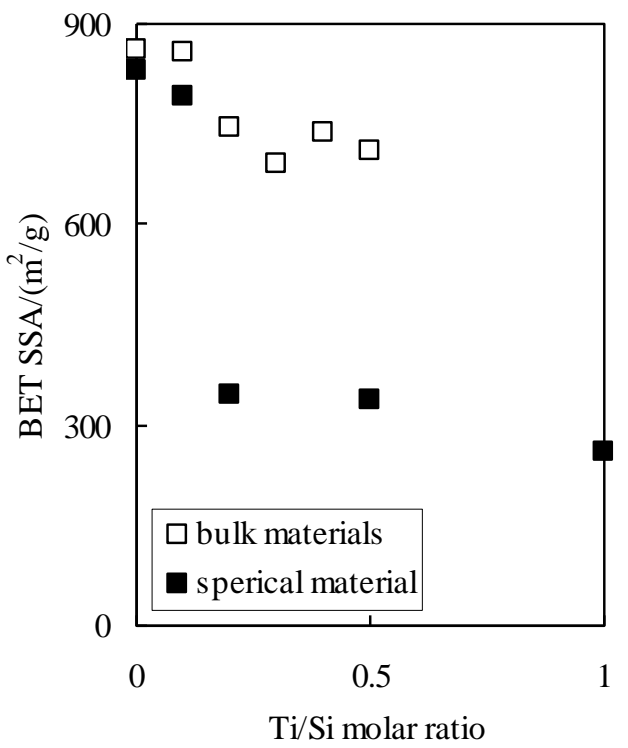


Fig.4

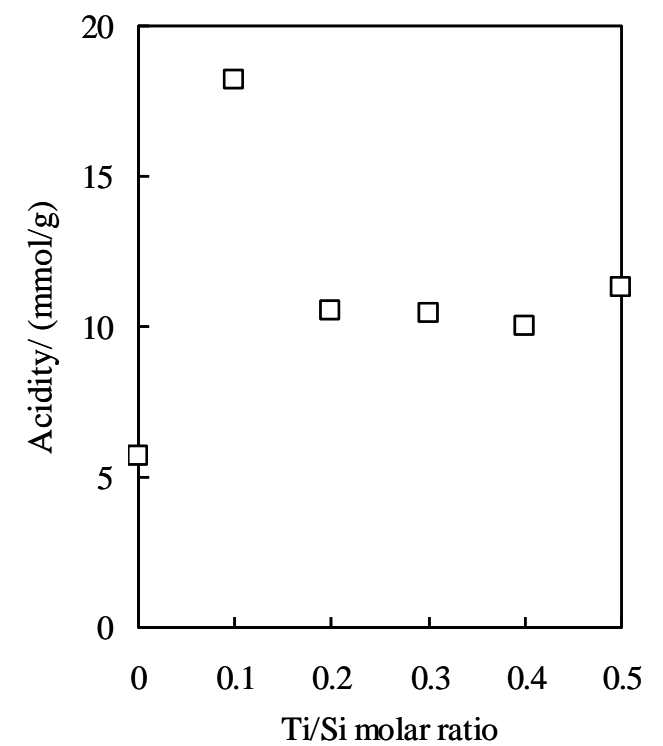


Fig.5

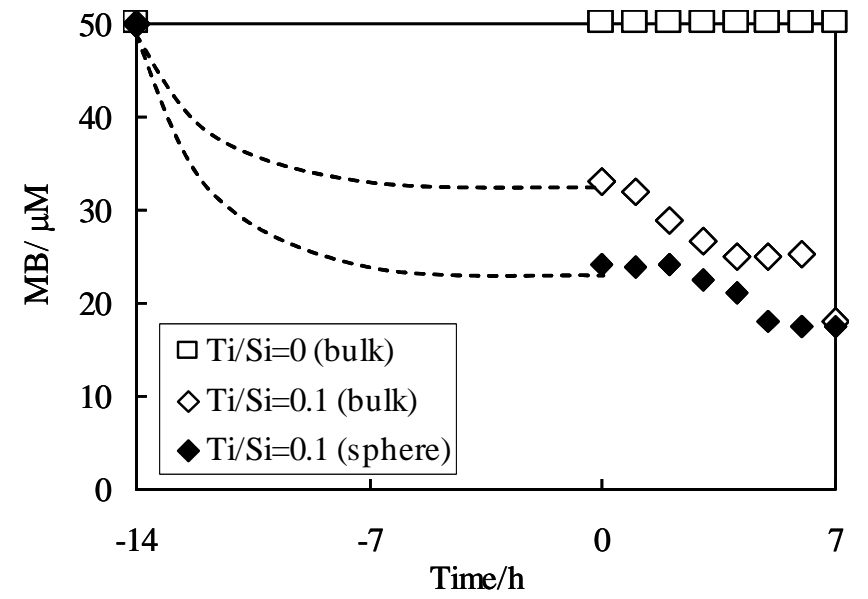

